\title{
Electrochemical Degradation of Bisphenol A in Water with/without Ce(IV) Addition
}

\author{
Kuo-Lin Huang ${ }^{1, *}$, Yu-Ching Chu ${ }^{1}$, How-Ran Chen ${ }^{1}$, Yi-Ming Kuo ${ }^{2}$ \\ ${ }^{1}$ Department of Environmental Science and Engineering, National Pingtung University of Science and \\ Technology, Pingtung 91201, Taiwan (ROC) \\ ${ }^{2}$ Department of Safety Health and Environmental Engineering, Chung Hwa University of Medical \\ Technology, Tainan City 71703, Taiwan (ROC) \\ *E-mail: huangk1@mail.npust.edu.tw
}

doi: $10.20964 / 2017.12 .600$

Received: 29 September 2017 / Accepted: 10 November 2017 / Published: 12 November 2017

This study investigates the degradation of bisphenol A (BPA) by electrooxidation on a boron-doped diamond (BDD) anode with/without $\mathrm{Ce}(\mathrm{IV})$ addition in $1 \mathrm{M} \mathrm{Na}_{2} \mathrm{SO}_{4}$ and real environmental water matrices: municipal wastewater treatment plant primary and secondary effluents (MWTPPE and MWTPSE, respectively), river water (RW), and groundwater (GW). The results show that the BPA degradation and TOC removal increased along with the current density $\left(0.25-0.75 \mathrm{~A} / \mathrm{cm}^{2}\right)$, while the BPA degradation decreased but the TOC removal increased when the temperature rose $\left(25^{\circ} \mathrm{C}-75^{\circ} \mathrm{C}\right)$. Similar efficiencies of BPA degradation or TOC removal were observed in $\mathrm{pH}$ 3-10 phosphate buffer solutions. At $0.5 \mathrm{~A} / \mathrm{cm}^{2}$ and $75^{\circ} \mathrm{C}$ in $1 \mathrm{M} \mathrm{Na}_{2} \mathrm{SO}_{4}$, complete $\mathrm{BPA}$ degradation was achieved using electrolysis (E), $\mathrm{E}+\mathrm{Ce}(\mathrm{IV}), \mathrm{Ce}(\mathrm{IV})$; however, the BPA degradation or TOC removal was in the order $\mathrm{Ce}(\mathrm{IV})>\mathrm{E}+\mathrm{Ce}(\mathrm{IV})>\mathrm{E}$, and complete TOC removal was only attained using E alone. In MWTPSE, the BPA electrochemical degradation efficiency achieved by adding chemical Ce(IV) was similar to that by adding $\mathrm{Ce}(\mathrm{IV})$ regenerated (R-Ce(IV)) from real spent thin-film transistor liquid-crystal display (TFT-LCD) Cr-etching solutions; nevertheless, the TOC removal was better for the former than for the latter. The rates of formation and degradation of $p$-benzoquinone (an intermediate from BPA electrochemical degradation) followed the order $\mathrm{E}+\mathrm{Ce}(\mathrm{IV})>\mathrm{E}>\mathrm{E}+\mathrm{R}-\mathrm{Ce}(\mathrm{IV})$. Without electrolysis, the $p$-benzoquinone could almost not be degraded when using $\mathrm{Ce}(\mathrm{IV})$ alone. Similar degradation efficiencies of BPA in MWTPPE, MWTPSE, RW, and GW were observed $\left(k=(3.68-6.07) \times 10^{-3} \mathrm{~s}^{-1}\right)$, but the complete TOC removal could not be obtained in $\mathrm{RW}$, despite reaching complete $p$ benzoquinone degradation in the four matrices.

Keywords: electrochemical degradation; bisphenol A; p-benzoquinone; boron-doped diamond (BDD) electrode; mineralization

\section{FULL TEXT}


(C) 2017 The Authors. Published by ESG (www.electrochemsci.org). This article is an open access article distributed under the terms and conditions of the Creative Commons Attribution license (http://creativecommons.org/licenses/by/4.0/). 